\title{
Self-adaptive fuzzy-PID controller for AGC study in deregulated Power System
}

\author{
Subhadra Sahoo ${ }^{1}$, Narendra Kumar Jena ${ }^{2}$, Geetanjali Dei ${ }^{3}$, Binod Kumar Sahu ${ }^{4}$ \\ 1,2,4 Department of Electrical Engineering, ITER, Siksha 'O' Anusandhan (Deemed to be University), Bhubaneswar, \\ Odisha, India. \\ ${ }^{3}$ Kalinga Institute of Industrial Technology (KIIT), Bhubaneswar, Odisha, India.
}

\begin{tabular}{l} 
Article Info \\
\hline Article history: \\
Received Jun 22, 2019 \\
Revised Nov 14, 2019 \\
Accepted Dec 5, 2019 \\
\hline Keyword: \\
Automatic Generation control \\
Fuzzy Logic Control \\
Power System Stability \\
Deregulated Power System
\end{tabular}

\begin{abstract}
The aim of this paper elucidates the automatic generation control (AGC) issues in a large-scale interconnected power system incorporating high voltage direct current (HVDC) link under the deregulated environment. To deal with all possible sorts of power transactions in the energy market, a secondary robust, and intelligent controller for AGC is necessary. So, a classical proportionalintegral-derivative (PID) controller assisted by fuzzy logic is configured as a novel self-adaptive Fuzzy-PID (SA-FPID) controller to ameliorate the dynamic performance of the restructured system over conventional PID and Fuzzy-PID controllers. In self-adaptive Fuzzy-PID controller unlike the Fuzzy-PID controller, the output scaling factors are tuned dynamically while the controller is functioning. The controllers used in this paper are designed by enumerating different gains and scaling factors, applying a budding natureinspired algorithm known as Wild Goat Algorithm (WGA). The superior dynamic performance of frequency and tie-line power deviation under SAFPID in comparison to its' counterparts is investigated by dispatching the scheduled and unscheduled power under different contracts such as poolco based transaction, bilateral transaction and contract violation-based transaction through the tie-line. In addition, the potential of the proposed SAFPID controller is examined by taking a practical model. Further, the dynamic response under parameter variation and random load perturbation is evaluated which confers the robustness of the proposed controller.
\end{abstract}

Copyright (C) 2019 Institute of Advanced Engineering and Science. All rights reserved.

\section{Corresponding Author:}

Binod Kumar Sahu,

Department of Electrical Engineering, ITER,

Siksha 'O' Anusandhan (Deemed to be University),

Bhubaneswar, Odisha, India.

Email: binoditer@gmail.com

\section{INTRODUCTION}

In an interconnected power system, the role of the automatic generation control (AGC) is to achieve better frequency regulation and to maintain the tie-line power flow at scheduled level irrespective of load changes in any area. AGC plays a vital role for each generating unit to control the system frequency and tieline power flow among different control areas of an interconnected power system [1-2]. Whenever the load changes sharply, the stability of frequency cannot be achieved suddenly by the speed governor alone. So, a secondary controller is essential to keep the frequency at the nominal value [3-5]. In the present scenario, the power system has been restructured by which efficiency of power industries increases and energy consumption cost decreases. To do so, the energy market is deregulated and it is governed by different players such as generating companies (GENCOs), transmission companies (TRANSCOs), distribution companies (DISCOs), and an administrator, ISO (Independent System Operator). In the deregulated environment each DISCO has the liberty to demand electrical power from any GENCO and GENCO can sell power to any DISCO, for which 
electric market becomes more competitive to serve the end users providing a cost effective quality power. In a restructured environment, AGC issue is magnified to deal with the power mismatch between the generation and load. To restore the stability of the system, a robust secondary controller is necessary.

Different researchers have proposed several control strategies and optimization techniques related to automatic generation control. Different types of controller like Integral (I) [6], Proportional-Integral (PI) [7], Proportional-Integral-Derivative (PID) [8], Integral-Double Derivative [9], Fractional Order PID [10] and Proportional-Integral-Double Derivative (PIDD) [11], optimal control [12] have been applied to study the AGC problem in an interconnected conventional power system. But in the deregulated environment, different researchers proposed different control strategies for AGC issues. Hota et al. [13] studied I, PI, ID, and PID controllers using differential evolution for AGC in the deregulated system. Debbarma et al. [14] developed a fractional-order (FO) proportional-integral-derivative (FOPID) controller tuned with a bacterial foraging optimisation algorithm for two-area and three-area power system under the deregulated environment. FOPI, and FOPID controllers are designed by applying a sine-cosine algorithm (SCA) for LFC in the deregulated environment by Tasnin et al. [15]. Morsali et al. [16] addressed the enhancement of AGC incorporating SSSC in a restructured power system endorsing fractional order controller. Rajbongshi et al. [17] demonstrated the performance of a deregulated power system employing a FOPID controller under the influence of interline power flow controller and power system stabiliser. Nagendra et al. [18] studied the AGC of a restructured power system employing PID as a secondary controller. Nayak et al. [19] worked on FOPID controller for the AGC of two area power system using group hunt search (GHS) and Quasi-oppositional GHS (QOGHS) algorithm. Baskar et al. [20] focused on the calculation of indices of ancillary services requirement (ASR) and used PID with derivative filter (PIDF) controller for AGC in a restructured power system. Parmar et al. [21] considered an optimal feedback controller for multi-source power generation in the deregulated environment. In the advent of sophisticated power electronics devices, HVDC in parallel with AC link has emerged to be an alternative link for power system by which power flow oscillations in AC system can be damped out effectively by controlling DC power. The dynamic performance of the power system is improved by the AC-DC link [22, 23]. Prakash et al. [22] proposed inertia emulsion based controller (INEC) used to store the energy of DC tielink and cascaded two degrees of freedom PI controller and fractional order proportional plus derivative controller with filter (PI-FOPDN) as a prime controller for LFC of interconnected power system having different renewable sources. Shankar et al. [24] focused on the impact of unified power flow control (UPFC) incorporating with $\mathrm{AC} / \mathrm{DC}$ link for AGC issues in a multi-area deregulated power system using a PID controller. Arya et al. [25] designed optimal PI regulator considering AC/DC link for the LFC of a multi area multi source restructured system. Srinivasa et al. [26] proposed a thyristor controlled phase shifter (TCPS) based hydro-thermal system under deregulation using a fuzzy logic controller. Brinda et al. [27] examined the LFC in a restructured power system subjecting PI, as well as fuzzy controller incorporating dead band and boiler dynamics non-linearities. Fathy et al. [28] used mine blast algorithm based fuzzy-PID controller to analyse the LFC of an interconnected system under the restructured environment. A grey wolf optimisation technique is introduced to tune the gains of a fuzzy-PID controller with a low pass filter for the AGC of a multiarea restructured power system in [29]. Afrakhte et al. [30] designed an optimal fuzzy logic controller as a secondary controller for AGC in a restructured power system having different distributed generation sources. Fractional order fuzzy PID controller (FOFPID) tuned by BFOA is suggested by Arya et al [31] for AGC of deregulated power system. A fuzzy PID controller with derivative filter and fractional order integral controller optimised by cuckoo optimisation algorithm is proposed for LFC by Gheisarnejad et al. [32]. Arya [33] recommended Fractional order fuzzy PID controller (FOFPID) for a two area multi source power system having Redox flow battery (RFB) as energy storage system.

From the above discussion for the best of knowledge, the adaptive fuzzy-PID controller has not used any more for the AGC issues in the conventional and restructured power system. Besides this, it is observed that the conventional PID controller may not give a satisfactory response to the parametric variation, higher order system with nonlinearity and unscheduled power transactions. So Fuzzy-PID controller is employed to mitigate the aforementioned problem. The fuzzy logic based PID controller is less sensitive to the parametric variation of the system and gives a robust performance to the higher order non-linear system. But the design of this controller is based on high intuition and experience of the researcher. It is quintessential to define proper input and output membership functions as well as input and output scaling factors (SFs) and other controller parameters. To overcome the trial and error selection method, the Fuzzy-PID controller has made adaptive by which the scaling factors are tuned dynamically while the controller is functioning. So in this paper, a maiden attempt is taken to design an adaptive fuzzy-PID controller optimised by a recent computational technique named Wild Goat Algorithm (WGA) [34] for AGC in a restructured environment.

The main objectives of the proposed work are

i. To study the dynamic performance of a multi-source power system incorporating GRC nonlinearity and AC/DC link, under a deregulated environment. 
ii. To ameliorate the dynamic performance of PID, and fuzzy-PID (FPID) controller, a novel self-adaptive fuzzy-PID (SA-FPID) controller is designed to employ in the presided system.

iii. To enumerate the gains and scaling parameters, a newly developed bio-inspired WGA algorithm [34] is applied by endorsing ITAE objective function.

iv. The superior dynamic performance of adaptive fuzzy-PID (SA-FPID) controller in comparison to PID, and FPID is delineated under all kinds of transactions.

$\mathrm{v}$. Robustness of the proposed controller is investigated by subjecting parameter variation and random load perturbation in area-1.

\section{POWER SYSTEM MODELLING UNDER THE DEREGULATED ENVIRONMENT}

In this paper, the model of reheat thermal, hydro and nuclear turbine of two area restructured power system is considered for the study of AGC as depicted in Figure 1. In a power plant, the power generation can be changed only at a specified rate known as GRC. In this paper, a GRC of 3\% per min for thermal units and $270 \%$ per min for raising and $360 \%$ per min for lowering generation in hydro units are considered. The mathematical modelling of these three units are referred from [35] and various parameters are illustrated in the appendices.

In a deregulated power system there are different players take part to sell and buy electric power. GENCOs sell power to DISCOs as per the contract made between GENCOs and DISCOs. If DISCOs contract power from the GENCOs of the same area then it is known as poolco based transaction. If DISCOs contract power from the GENCOs of the other area then it is known as a bilateral transaction. If DISCOs violate the contract and demand more power than the specified value then it is known as a contract violation based transaction. The contracts of DISCOs with GENCOs are given by disco partition matrix (DPM). In DPM the number of rows indicates the number of GENCOs and those of columns indicates the number of DISCOs. The ' $i j^{\text {th }}$ ' element of the matrix represents a fraction of total load contracted by ' $j{ }^{\text {th }}$. DISCO towards $i^{\text {th }}$ GENCO.

In the proposed study two areas are considered. Each area consists of three GENCOs and three DISCOs as shown in Figure 1. Hence the corresponding DPM matrix is given by:

$$
D P M=\left[\begin{array}{llllll}
c p f_{11} & c p f_{12} & c p f_{13} & c p f_{14} & c p f 15 & c p f_{16} \\
c p f_{21} & c p f_{22} & c p f_{23} & c p f_{24} & c p f_{25} & c p f_{26} \\
c p f_{31} & c p f_{32} & c p f_{33} & c p f_{34} & c p f_{35} & c p f_{36} \\
c p f_{41} & c p f_{42} & c p f_{43} & c p f_{44} & c p f_{45} & c p f_{46} \\
c p f_{51} & c p f_{52} & c p f_{53} & c p f_{54} & c p f_{55} & c p f_{56} \\
c p f_{61} & c p f_{62} & c p f_{63} & c p f_{64} & c p f_{65} & c p f_{66}
\end{array}\right]
$$

Where ' $c p f^{\prime}$ ' stands for contract participation factor.

The GENCO is supposed to provide load demanded by DISCOs of the same and the other areas. The steady state power flow in the tie-line is given by

$$
\begin{aligned}
\Delta P_{\text {tiel-2,sch. }}= & \text { Demand of DISCOs in area } 2 \text { from GENCOs of area1 } \\
& - \text { Demand of DISCOs in areal from GENCOs of area } 2 \\
\Delta P_{\text {tiel-2,actual }} & =\frac{2 \pi T_{12}}{s}\left(\Delta f_{1}-\Delta f_{2}\right) \\
\Delta P_{\text {tiel-2,error }}= & \Delta P_{\text {tiel-2,actual }}-\Delta P_{\text {tiel-2,schedule }}
\end{aligned}
$$
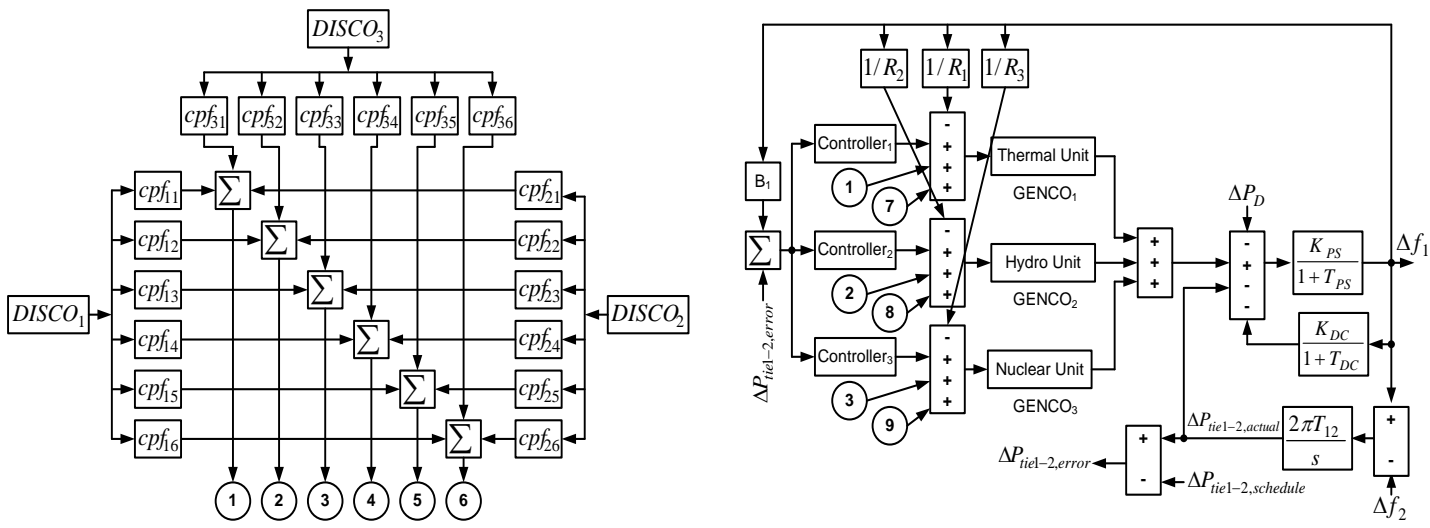
Figure 1. Area-1 of the proposed Power System Model.

This error in tie-line power is used to determine the area control errors (ACEs) of area-1 and area-2 using the relation

$$
\begin{gathered}
A C E_{1}=B_{1} \Delta f_{1}+\Delta P_{\text {tiel-2,error }} \text { and } \\
A C E_{2}=B_{2} \Delta f_{2}+\Delta P_{\text {tie } 2-1, \text { error }} \\
\Delta P_{\text {tie2-1,error }}=a_{12} \Delta P_{\text {tiel-2,error }} \\
\text { Where, } a_{12}=-\left(\frac{\mathrm{P}_{\mathrm{r} 1}}{\mathrm{P}_{\mathrm{r} 2}}\right)
\end{gathered}
$$

Where, $P_{r 1} \& P_{r 2}$ are the power ratings of area-1 and area-2 respectively.

\section{SELF-ADAPTIVE FUZZY-PID (SA-FPID) CONTROLLER DESIGN}

PID controller is the most commonly used controller in the electrical power industry because it is simple in design, reliable, easily understood and the favourable ratio between performance and cost. It consists of three basic modes, the proportional mode, the integral and the derivative modes. A proportional controller reduces the rise time, an integral controller eliminates the steady-state error, but it gives the worse transient response and a derivative controller increases the stability of the system, reduces the overshoot, and improves the transient response. In this study three PID controllers, one for the thermal unit, one for the hydro unit and one for the nuclear unit are used to improve the performance of the AGC system. Therefore, for designing optimal PID controller we need to optimally design nine gains (three for each PID controller).

The complexity of the power system is increasing day by day because of the immense growth in load demand with good quality and uninterrupted power supply. Conventional PID controller may not provide the satisfactory solutions for the complex power system hence an artificial intelligence based PID controller is preferred. Fuzzy logic has gained popularity amongst others because of its computing approach based on "degrees of truth" rather than the usual "true or false". The fuzzy logic based PID controller is less sensitive to the parametric variation of the system and gives a robust performance to the higher order non-linear system. Structure of a fuzzy-PID controller is shown in Figure 2 (a).

But the design of the FPID controller is based on high intuition and experience of the researcher. So the input and output membership functions as well as input and output scaling factors (SFs) and other controller parameters are defined by trial and error method. To overcome this human error, the Fuzzy-PID controller has made adaptive by which the scaling factors are tuned dynamically while the controller is functioning. The selfadaptive fuzzy-PID (SA-FPID) controller is portrayed in Figure 2 (b). Structure of membership functions for both FPID and SA-FPID are given in Figure 2 (c) \& Figure 2 (d). The operation of these controllers is carried by the rule bases as intuited in Table $1 \& 2$. The fuzzy logic controller uses the following steps for its operation.

i. Fuzzification: - It is the process of conversion of crisp input to a linguistic variable with the help of membership functions. In this study, five membership functions namely negative big (NB), negative small $(\mathrm{NS})$, zero (Z), positive small (PS) and positive big (PB) are considered. The general structure of the membership function is shown in Figure 2 (c) and (d). Triangular membership functions are taken considered because of its simple structure and less computational burden.

ii. Interface engine: - It converts the fuzzy input to fuzzy output using if-then type fuzzy rules. Since there are five membership functions for each input, 25 sets of fuzzy rules are required to get the fuzzy output. Rule base used in the proposed work is depicted in Table 1 and 2.

iii. Defuzzification: - It is the process of conversion of fuzzy output into crisp. There are many defuzzification processes. In this paper, the most commonly used centre of gravity defuzzification technique is used to obtain a crisp output.
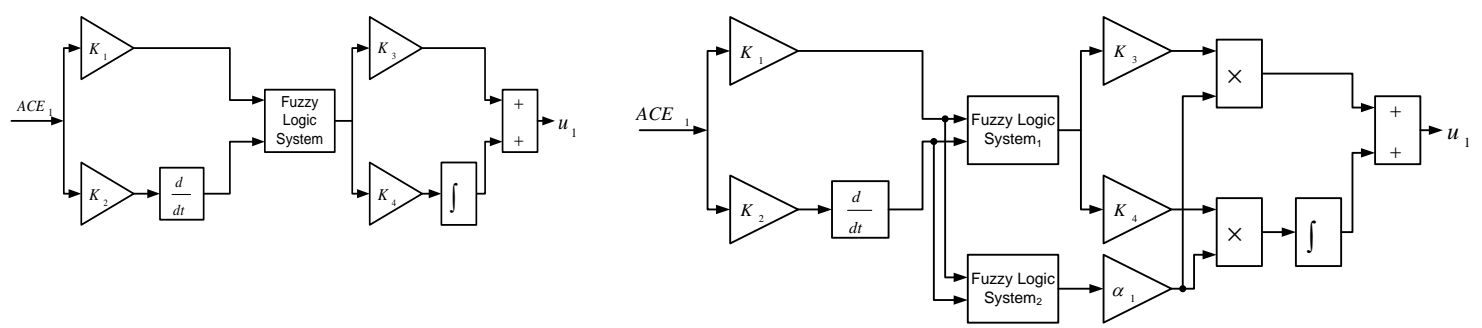

(a)

(b) 


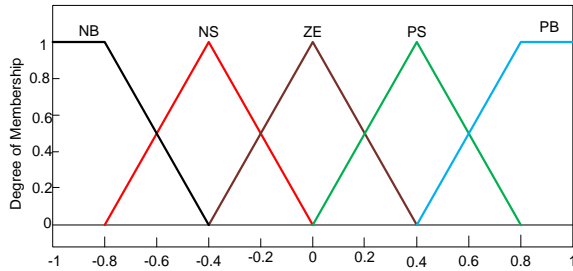

(c)

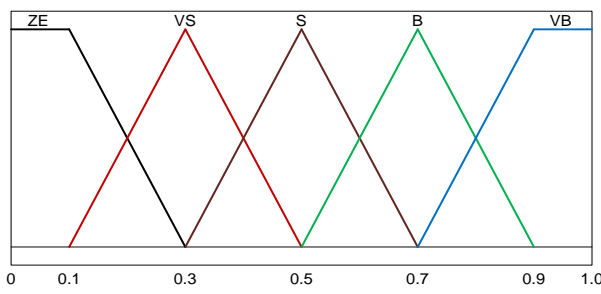

(d)

Figure 2. (a) Structure of a fuzzy-PID controller (b) Structure of a self-adaptive fuzzy-PID (SA-FPID) controller(c) Membership function structure for both the inputs of fuzzy logic system 1 \& system 2 and output of fuzzy logic system1 (d) Membership function structure for output of fuzzy logic system2.

Table 1. Rule base for fuzzy logic system.

\begin{tabular}{|c|c|c|c|c|c|c|c|c|c|c|c|}
\hline \multicolumn{6}{|c|}{ Fuzzy Logic System 1} & \multicolumn{6}{|c|}{ Fuzzy Logic System 2} \\
\hline \multirow{2}{*}{$\mathrm{ACE}$} & \multicolumn{5}{|c|}{$\triangle \mathbf{A C E}$} & \multirow{2}{*}{$\mathrm{ACE}$} & \multicolumn{5}{|c|}{$\triangle \mathrm{ACE}$} \\
\hline & NB & NS & $\mathbf{Z E}$ & PS & PB & & NB & NS & $\mathbf{Z E}$ & PS & PB \\
\hline NB & NB & NB & NS & NS & $\mathrm{ZE}$ & NB & VB & B & $S$ & VS & ZE \\
\hline NS & NB & NS & NS & $\mathrm{ZE}$ & PS & NS & B & S & VS & $\mathrm{ZE}$ & VS \\
\hline $\mathbf{Z E}$ & NS & NS & $\mathrm{ZE}$ & PS & PS & $\mathbf{Z E}$ & $S$ & VS & $\mathrm{ZE}$ & VS & S \\
\hline PS & NS & $\mathrm{ZE}$ & PS & PS & $\mathrm{PB}$ & PS & VS & $\mathrm{ZE}$ & VS & S & B \\
\hline PB & $\mathrm{ZE}$ & PS & PS & $\mathrm{PB}$ & PB & PB & $\mathrm{ZE}$ & VS & S & B & VB \\
\hline
\end{tabular}

In SA-FPID controller the gain parameters $\mathrm{K}_{3}$ and $\mathrm{K}_{4}$ are tuned dynamically by the help of second fuzzy logic controller which is portrayed in the result and discussion section.

\section{WILD GOAT ALGORITHM (WGA) ALGORITHM}

It is a new robust and powerful nature-inspired algorithm introduced by Alireza et al. [34]. WGA is developed with the inspiration from the living style of wild goats in the mountains. They often live together in groups or herds in the mountains and also climb or move down together. Members of each group follow their leader and previous members' path whereas leaders move with respect to its personal experience and follow the other leaders' path. During the movement, the leaders of each group consult together to exchange experiences about the direction and quality of routing the path. This process will continue to the point that only one herd remains to reach the mountaintop. This group is known as the best group among others. Various steps involved in WGA are described below:

\section{Initialisation phase}

The total number of populations of wild goats $\left(N_{w g}\right)$ and maximum no of iteration (itermax) are selected arbitrarily. Position of each member in population is defined as

$$
w g_{i}=\left[x_{i, 1}, x_{i, 2}, \ldots \ldots x_{i, n \mathrm{var}}\right]
$$

Where, $i=1,2, \ldots \ldots N_{w g}$

The objective function of each wild goat is evaluated according to the defined problem.

$$
f\left(w g_{i}\right)=f\left[x_{i, 1}, x_{i, 2}, \ldots \ldots . x_{i, n \text { var }}\right]
$$

Since the values of objective function have a wide range of variation, they may not be a proper tool to compare the wild goats together. Hence another tool known as weight is introduced to measure the quality of each member. The weight of each $w g_{i}$ is defined as:

$$
W_{i}=\exp \left(-N_{\mathrm{var}} \frac{f\left(w g_{i}\right)-\min _{j}\left\{f\left(w g_{j}\right)\right\}}{\sum_{j=1}^{N_{w g}}\left(f\left(w g_{j}\right)-\min _{j}\left\{f\left(w g_{j}\right)\right\}\right)}\right)
$$

Where, $i=1,2, \ldots \ldots . N_{w g}$

The wild goat having optimum objective function has weight one and other wild goats have their weight in between 0 and 1 . Then the wild goats are sorted as per the weight. 
The $w g_{i} \mathrm{~s}$ which have higher value of weights are selected as leaders of the groups. Besides the leaders, other members are known as followers. The followers are divided among the groups based on the weight of the group's leader.

$N_{g} \rightarrow$ No. of groups or leaders; $N_{f}=N_{w g}-N_{g} ; W_{G_{i}} \rightarrow$ Weight of $i_{t h}$ group; $W_{l_{i}} \rightarrow$ Weight of $i_{t h}$ leader; $\alpha_{i} \rightarrow$ Share of $i_{t h}$ the group in entire followers; $N_{G_{i}} \rightarrow$ No. of followers of $i_{t h}$ the group.

\section{Movement phase}

Each member of each group including the leaders move towards the best position of the search space as per its movement vector. The movement vector is defined for the direction of movement of each member. Initial movement vector of all the wild goats is taken as zero.

The best leader moves in the direction of movement vector and best attempt whereas other leaders proceed in the direction of the leaders which have higher weight than them in addition to the direction of movement vector and their best attempt.

The movement vector after each iteration is modified as:

$$
v_{i}(t+1)=w \times v_{i}(t)+R \times \operatorname{rand} \times\left(p_{i}(t)-w g_{i}(t)\right)+c_{i}(t)
$$

The followers almost move like the leaders. In addition to moving towards their movement vector and their best attempt, they proceed in the direction of their group leaders and all the members of the group having a higher weight.

Position of the wild goats after each iteration is obtained as:

$$
w g_{i}(t+1)=w g_{i}(t)+v_{i}(t+1)
$$

\section{Revaluation}

After each iteration, the weights are re-calculated by using the new positions and members of the groups are sorted again.

\section{Group's cooperation}

The groups having more weight attract other group's followers with respect to their weights. The weights of a group can be defined as:

$$
W_{G_{i}}(t)=\frac{W_{l_{i}}(t)+\sum_{j=1}^{N_{G_{i}}} W_{j}(t)}{1+N_{G_{i}}}
$$

followers

The group with higher weight attracts more followers and group with lower weight losses more

Mutation

The mutation percentage ' $\mathrm{m}$ ' is set in such a way that the no. of mutated wild goats be less than the no. of groups in each iteration. Selection probability of each $w g$ for the mutation operation is inversely proportional to the group's weight as well as the weight of individual member on a random basis. Mutation does not include group leaders. After evaluation of mutated wild goats if the weight of each one of them is more than the weight of each group's leaders then that mutated $w g$ substitutes the group leaders in successive iteration.

\section{Moving towards reaching one group}

At the end of the last iteration only the most experienced group remains and the leader of that group reaches the best point in terms of the objective function. The no. of members of that group is $N_{w g}$. Hence the groups with low weight are missing their leader as well as followers during this process.

\section{RESULTS AND DISCUSSIONS OF THE SIMULATED TEST SYSTEM}

The model of the system under consideration is developed in MATLAB/SIMULINK environment and WGA program is written in .m file. Three cases related to deregulated power system are considered for the study. Three proposed controllers such as conventional PID, fuzzy-PID (FPID) and self-adaptive fuzzy-PID (SA-FPID) are optimally designed and implemented for dynamic analysis of all the three cases. ITAE is taken as an objective function to optimally design the controllers. The number of population and the maximum number of iterations are taken as 100. Best gains out of the 100 runs are taken as optimal controller gains and implemented in the AGC systems for dynamic analysis. Results obtained in all the three cases are discussed in the following sections. 


\subsection{Poolco based transaction}

In this case, DISCOs \& GENCOs of the same area have transactions contracts i.e. total demand of DISCOs of area-1 is to be supplied by GENCOs of area-1. Demands of DISCOs from available GENCOs are simulated using the DPM matrix expressed in equation 14. In this case load disturbance of $0.01 \mathrm{pu}$. is assumed only in area-1. The load disturbances for $\mathrm{DISCO}_{1}, \mathrm{DISCO}_{2}, \& \mathrm{DISCO}_{3}$ are $0.01 \mathrm{pu}$. i.e. $\Delta \mathrm{PL}_{1}=\Delta \mathrm{PL}_{2}=\Delta \mathrm{PL}_{3}$ $=0.01 \mathrm{pu}$., and $\Delta \mathrm{PL}_{4}=\Delta \mathrm{PL}_{5}=\Delta \mathrm{PL}_{6}=0$. So the total load disturbance in area-1 is $\Delta \mathrm{P}_{1}=0.03 \mathrm{pu}$. The DPM matrix considered here is expressed as:

$$
D P M=\left[\begin{array}{cccccc}
0.333 & 0.333 & 0.333 & 0 & 0 & 0 \\
0.333 & 0.333 & 0.333 & 0 & 0 & 0 \\
0.333 & 0.333 & 0.333 & 0 & 0 & 0 \\
0 & 0 & 0 & 0 & 0 & 0 \\
0 & 0 & 0 & 0 & 0 & 0 \\
0 & 0 & 0 & 0 & 0 & 0
\end{array}\right]
$$

The GENCO output power is calculated as:

$$
\Delta P_{M_{i}}=\sum_{j} c p f_{i j} \times \Delta P_{L_{j}}
$$

Hence the output power of $\mathrm{GENCO}_{1}, \mathrm{GENCO}_{2}, \mathrm{GENCO}_{3}, \mathrm{GENCO}_{4}, \mathrm{GENCO}_{5}$ and $\mathrm{GENCO}_{6}$ are $0.00999 \mathrm{pu}, 0.00999 \mathrm{pu}, 0.00999 \mathrm{pu}, 0 \mathrm{pu}, 0 \mathrm{pu}$ and $0 \mathrm{pu}$ respectively. Area participation factors for thermal, hydro and nuclear generating units are taken as $0.5435,0.3260$ and 0.1305 respectively for both areas. Different types of controllers are optimised using the proposed wild goat algorithm. The response of WGA optimised PID controller, WGA optimised Fuzzy-PID controller, WGA optimised self-adaptive Fuzzy-PID controller are compared. The Simulation results are compared with other controllers. The response of the system frequency deviation in area-1, frequency deviation in area-2, and tie-line power deviation are shown in Figure 3 (a), (b), and (c) respectively. The performance of the controllers in terms of overshoots and settling time is better in case of the proposed WGA optimised controller.

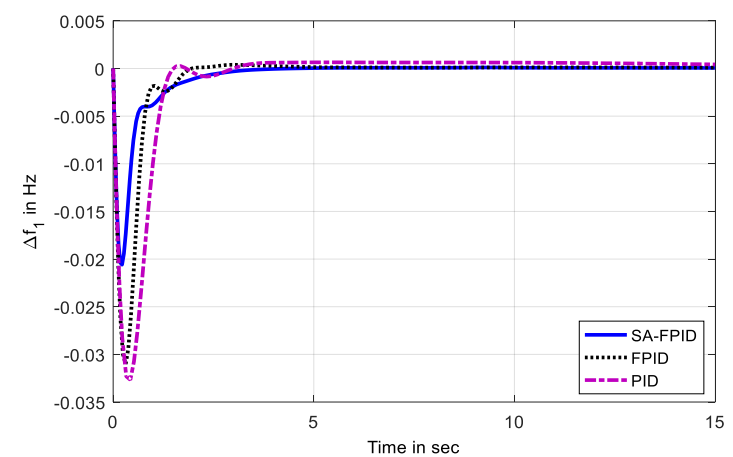

(a)

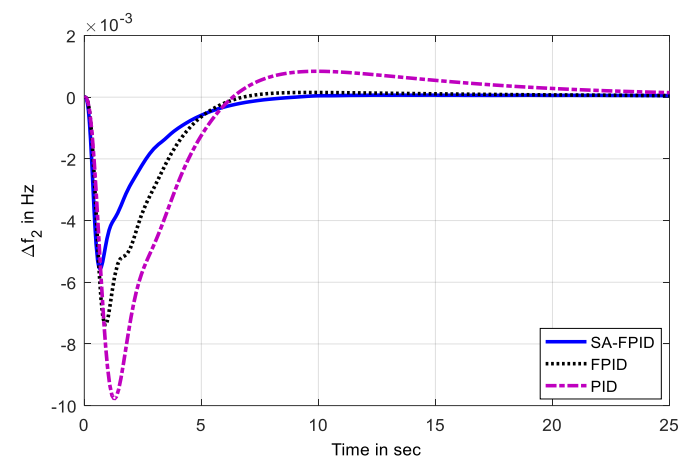

(b)

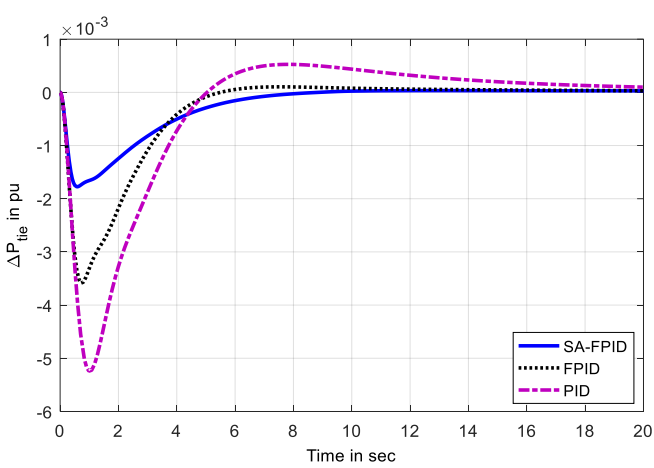

(c)

Figure 3. (a) Frequency deviation of area-1 under poolco transaction (b) Frequency deviation of area-2 under poolco transaction (c) Tie line power deviation under Poolco transaction.

The corresponding performance index in terms of ITAE and settling time of frequencies and tie-line power deviations are shown in Table 2. From Table 2, it is clear that with the same system and same operating 
condition the value of ITAE (0.1536) is minimum in case of adaptive Fuzzy PID controller tuned with WGA compared with (0.1718) for WGA tuned Fuzzy PID controller \& (0.4822) for WGA tuned PID controller. The settling time of frequency deviation in area- 1 for WGA tuned adaptive Fuzzy-PID controller is $0.57 \mathrm{~s}$, in case of WGA tuned Fuzzy-PID controller is $0.80 \mathrm{~s}$, and in case of WGA tuned PID controller is $1.18 \mathrm{~s}$. Similar is the case for other controllers for frequency deviation of area-2 and tie line power deviation. Consequently, better performance in terms of minimum settling time of frequencies and tie-line power deviation is achieved with WGA optimised adaptive Fuzzy-PID controller compared to other controllers. As observed from the Figure 3 (a), (b), and (c), better dynamic performance is obtained with WGA optimised SA-FPID controller, with less overshoot and undershoot for frequencies and tie line power deviation compared with other controllers. From the above assessment, it is found that WGA optimised SA-FPID controller performed better than WGA optimised Fuzzy-PID controller \& WGA optimised PID controller.

Table 2. Performance analysis under various transactions.

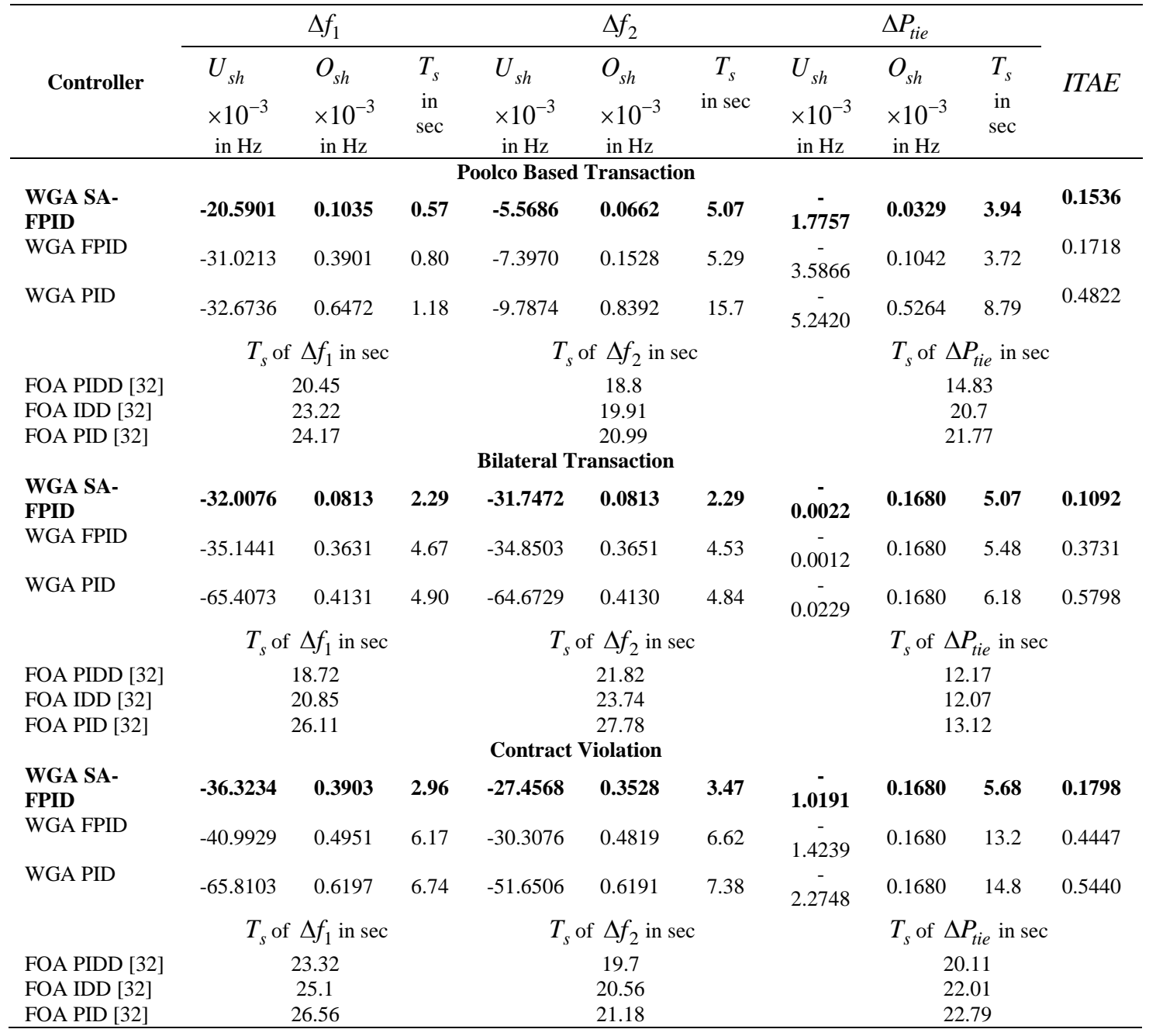

\subsection{Bilateral Transaction}

In Bilateral transaction, DISCOs have the liberty to deal with any of the GENCOs of the same area or with other areas. The assignment of AGC is accomplished through the following DPM.

$$
D P M=\left[\begin{array}{cccccc}
0.2 & 0.25 & 0.6 & 0.2 & 0.1 & 0 \\
0.2 & 0.15 & 0 & 0.2 & 0.1 & 0.1666 \\
0.1 & 0.15 & 0 & 0.2 & 0.2 & 0.1666 \\
0.2 & 0.15 & 0.4 & 0 & 0.2 & 0.3666 \\
0.2 & 0.15 & 0 & 0.2 & 0.2 & 0.1666 \\
0.1 & 0.15 & 0 & 0.2 & 0.2 & 0.1666
\end{array}\right]
$$


The load disturbance in each DISCOs is considered as $0.01 \mathrm{pu}$. Load demanded by each DISCO is taken as $0.01 \mathrm{pu}$. Hence in area-1, the local load is $0.03 \mathrm{pu}$. The local load in area- 2 is $0.03 \mathrm{pu}$. The GENCO outputs are $0.0117 \mathrm{pu}, 0.0036 \mathrm{pu}, 0.0081 \mathrm{pu}, 0.0131 \mathrm{pu}, 0.0091$ and 0.0081 respectively. The Area control error participation factors are $\mathrm{apf}_{1}=0.5435, \mathrm{apf}_{2}=0.3260, \mathrm{apf}_{3}=0.1305$ for both areas. In the case of the bilateral transaction, the results obtained from the simulation study depicts that the value of ITAE is 0.1092 in case of WGA optimised self-adaptive Fuzzy-PID controller. The value of ITAE for WGA tuned fuzzy-PID controller is 0.3731 which is better than the value obtained using WGA tuned PID controller (0.5798).

From the analysis, it is clear that WGA optimised adaptive Fuzzy-PID controller shows better performance than other controllers. The settling time of frequency deviation of area-1, the frequency deviation of area-2 and tie line power deviation obtained from the simulation of WGA optimised PID controller are 4.49 s, $4.84 \mathrm{~s}$, and $6.18 \mathrm{~s}$ respectively. In case of WGA optimised Fuzzy-PID controller the settling time of frequency deviation of area-1, the frequency deviation of area-2 and tie line power deviation obtained, are $4.67 \mathrm{~s}, 4.53 \mathrm{~s}$, and $5.48 \mathrm{~s}$ respectively. Similarly, in case of WGA optimised self-adaptive Fuzzy-PID controller the settling time of frequency deviation of area-1, the frequency deviation of area-2 and tie-line power deviation are 2.29 s, 2.29 s, and 5.07 s respectively. Figure 4 (a), (b) and (c) show that the performance in terms of overshoots and settling time is better in case of the proposed WGA optimised self-adaptive Fuzzy-PID controller.

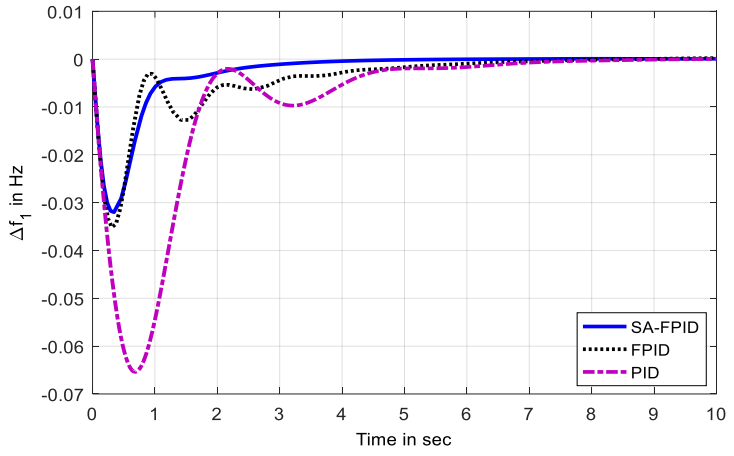

(a)

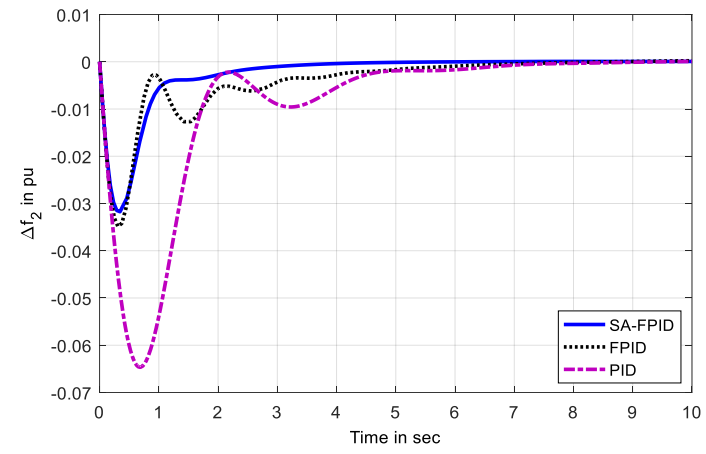

(b)

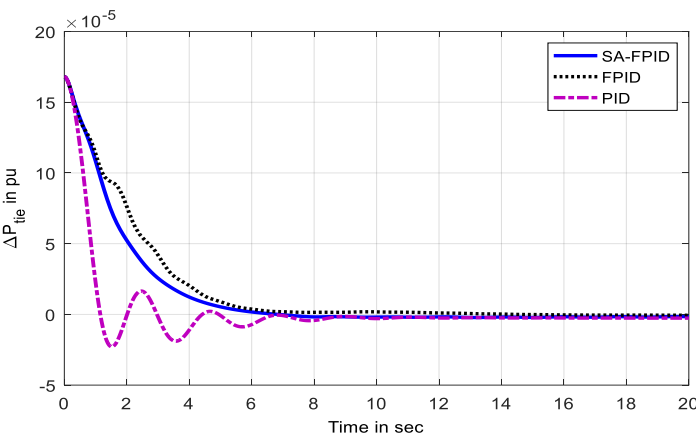

(c)

Figure 4. (a) Frequency deviation of area-1 under bilateral transaction (b) Frequency deviation of area-2 under bilateral transaction, (c) Tie line power deviation under bilateral transaction.

From the simulation results, and Table 2, it is clear that minimum value of settling time of frequency deviation of area-1 is obtained with WGA SA-FPID (2.29 s) controller compared with WGA FPID (4.67 s), WGA PID (4.9 s), FOA PIDD (18.72 s) and FOA IDD (20.85 s) controllers for bilateral transaction. Similarly in case of settling time of frequency deviation of area-1 is $2.29 \mathrm{~s}$ which is minimum as compared with WGA FPID (4.53 s), WGA PID (4.84 s), FOA PIDD (21.82 s), FOA IDD (23.74 s) and FOA PID (27.78 s) controllers. The settling time of tie-line power deviation is minimum (5.07 s) in case of WGA SA-FPID controller in comparison with WGA FPID (5.48 s), WGA PID (6.18 s), FOA PIDD (12.17 s), FOA IDD (12.07 s) and FOA PID (13.12 s) controllers.

\subsection{Contract Violation}

In this case, the power demanded by the DISCO may be more than that of the contracted power. By demanding more power, DISCO may deny the contract. This extra amount of power demand is the uncontracted demand. In this case the effectiveness of the WGA optimised fuzzy PID controller is tested against 
the uncertainties and load disturbances. Let consider the extra power demand by the $\mathrm{DISCO}_{1}$ is 0.01 pu. Load demanded by each DISCO is $0.01 \mathrm{pu}$. Hence in area- 1 the local load is, $\mathrm{DPL}_{1, \mathrm{loc}}=0.01+0.01+0.01+0.01=$ $0.04 \mathrm{pu}$. But the local load in area 2 remains same (0.03). To optimise SA-FPID, Fuzzy-PID, \& PID controller by WGA the following ACE factors for both areas are used.

$\operatorname{apf}_{1}=0.5435$, apf $_{2}=0.3260$, apf $_{3}=0.1305$

The DPM matrix in case of Contract Violation is same as in the bilateral transactions. The power generation of area 2 is same as in the bilateral transactions. Due to the uncontracted load demand of DISCO $\mathrm{D}_{1}$ the power generation of the GENCOs in area-1 is different. The GENCO outputs are $0.0119 \mathrm{pu}, 0.0036 \mathrm{pu}$, $0.0081 \mathrm{pu}, 0.0131 \mathrm{pu}, 0.0091$ and 0.0081 respectively.

In case of contract violation condition, the performance index and settling time of frequencies and tieline power are shown in Table 2. Minimum value of ITAE is obtained for WGA tuned SA-FPID controller $(\mathrm{ITAE}=0.1798)$ as compared with other controllers for contract violation case.

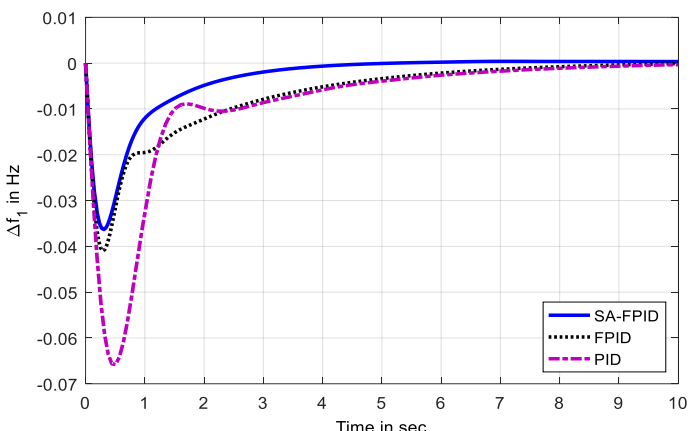

(a)

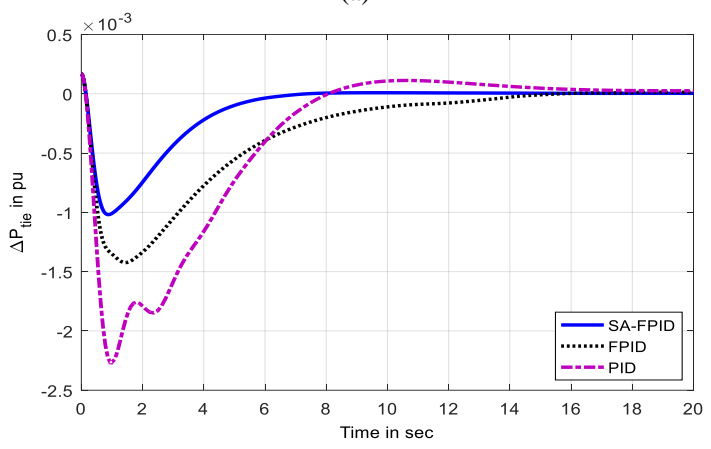

(c)

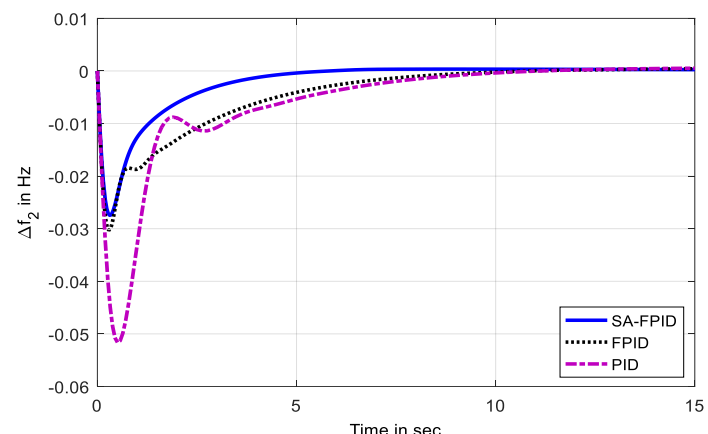

(b)

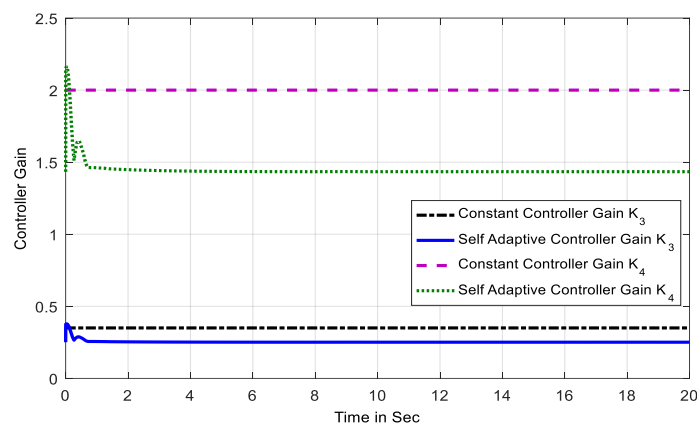

(d)

Figure 5 (a) Frequency deviation of area-1 under contract violation (b) Frequency deviation of area-2 under contract violation (c) Tie-line power deviation under contract violation (d) Controller gain variation.

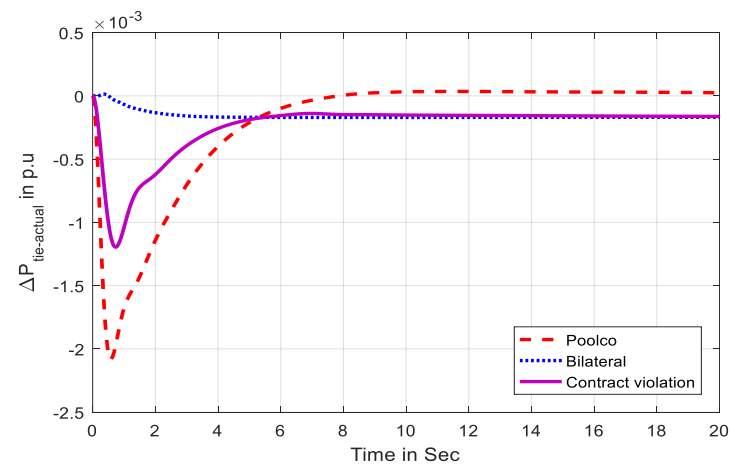

Figure 6. Transient response curve of actual tie-line powers.

The dynamic performances of the system with step load change of $4 \%$ in area-1 and $3 \%$ step load change in area-2 is shown in Figure 5 (a), (b), and (c). Moreover, the deviation of actual tie-line power for Poolco, Bilateral and contract violation is portrayed in Figure 6. Better performances are obtained with WGA tuned SA-FPID controller compared with other controllers. Adaptive-ness of the proposed SA-FPID controller 
is demonstrated in Figure 5(d) which clearly indicates the dynamic variation of the output scaling factors $\left(\mathrm{K}_{3}\right.$ and $\mathrm{K}_{4}$ ) employed in thermal system.

\subsection{Robustness Analysis}

Robustness analysis of the self-adaptive fuzzy PID controller is carried out by subjecting (a) variation of different parameters of the system (b) random load variation in area 1 . The standard deviation and mean values are tabulated in Table 3 by varying some crucial parameters such as $\mathrm{B}, \mathrm{R}, \mathrm{T}_{12}, \mathrm{~K}_{\mathrm{ps}}, \mathrm{T}_{\mathrm{ps}}, \mathrm{KH}_{1}$ by $\pm 10 \%$ band from their nominal values. From this table it is apparent that the deviation of peaks, troughs and settling times are meagre i.e. the designed SA-FPID controller tackles parametric variation easily. The standard deviation in Table 3 suffices the robustness of the proposed controller is perceived. Further the robustness of SA-FPID controller is examined by subjecting a random step load under contract violation as shown in Figure 7. From this figure, the dynamic response of frequency deviation in area 1 and the tie line power deviation is quite low which confers the robustness of SA-FPID controller.

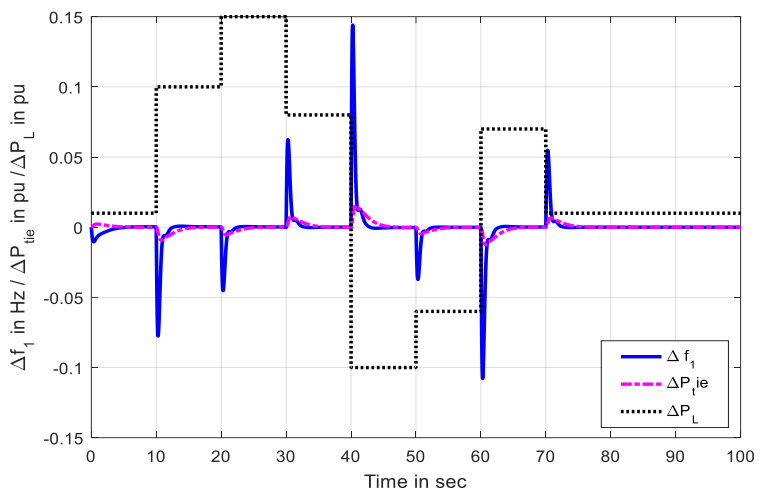

Figure 7. Frequency deviation and tie-line power deviation under random load variation.

Table 3. Performance analysis under parameter variation of the system.

\begin{tabular}{|c|c|c|c|c|c|c|c|c|c|}
\hline & \multicolumn{3}{|c|}{$\Delta f 1$} & \multicolumn{3}{|c|}{$\Delta f 2$} & \multicolumn{3}{|c|}{$\Delta P_{t i e}$} \\
\hline & $u_{s h}$ & $o_{s h}$ & $t_{s}$ & $u_{s h}$ & $o_{s h}$ & $t_{s}$ & $u_{s h}$ & $o_{s h}$ & $t_{s}$ \\
\hline $\begin{array}{l}\text { Standard } \\
\text { Deviation }\end{array}$ & $\begin{array}{c}8.3509 \\
\times 10^{-4}\end{array}$ & $\begin{array}{c}6.5938 \\
\times 10^{-5}\end{array}$ & 0.0780 & $\begin{array}{c}6.3553 \\
\times 10^{-4}\end{array}$ & $\begin{array}{l}6.593 \\
\times 10^{-4}\end{array}$ & 0.0780 & $\begin{array}{c}6.7566 \\
\times 10^{-4}\end{array}$ & $\begin{array}{c}2.7688 \\
\times 10^{-4}\end{array}$ & 0.0779 \\
\hline Mean & -0.0370 & $\begin{array}{c}4.000 \mathrm{x} \\
10^{-4}\end{array}$ & 2.8987 & -0.0275 & $\begin{array}{c}4.0000 \\
\times 10^{-4}\end{array}$ & 3.2457 & -0.0010 & $\begin{array}{c}2.0000 \\
\times 10^{-4}\end{array}$ & 4.4548 \\
\hline
\end{tabular}

\section{EXTENDED WORK}

\subsection{Power system Model}

To establish the recommended, SAFPID controller, a two equal area non-reheat thermal system is considered as shown in Figure 8. The system model and its parameters are taken from the reference [36]. The simulation and coding is done by MATLAB/SIMULINK version 2016b. The LFC of the given system is analysed by inserting a step load change of 0.01p.u in area1 and the Area Control error (ACE) is reduced through SAFPID controller.

\subsection{Result Analysis}

Here in this article for the analysis of the LFC, a two equal area thermal system is considered and the study is carried on by injecting SLP of $0.01 \mathrm{pu}$ at $\mathrm{t}=0 \mathrm{sec}$ in area1. SAFPID controller is employed for minimisation of ACE and to improve the stability. The frequency and tie-line power excursions are shown in the Figure 9. The gains of the proposed adaptive controller are optimised by Wild goat Algorithm (WGA). The results are compared with that of Fuzzy-PI (F-PI) controller as given in reference [36]. The performance indices are provided in Table 4. From the figures it is proved that SAFPID controller gives better transient performance than FPI controller [36] in terms of undershoot, overshoot and settling time except the overshoot of frequency deviation in area-1. So the SAFPID controller supersedes the FPI controller.

Table 4. Transient indices.

\begin{tabular}{ccccccc}
\hline & F-PI [36] & \multicolumn{4}{c}{ SA-FPID } \\
\cline { 2 - 3 } & $o_{s h}$ & $t_{s}$ & $u_{s h}$ & $o_{s h}$ & $t_{s}$ \\
\hline
\end{tabular}




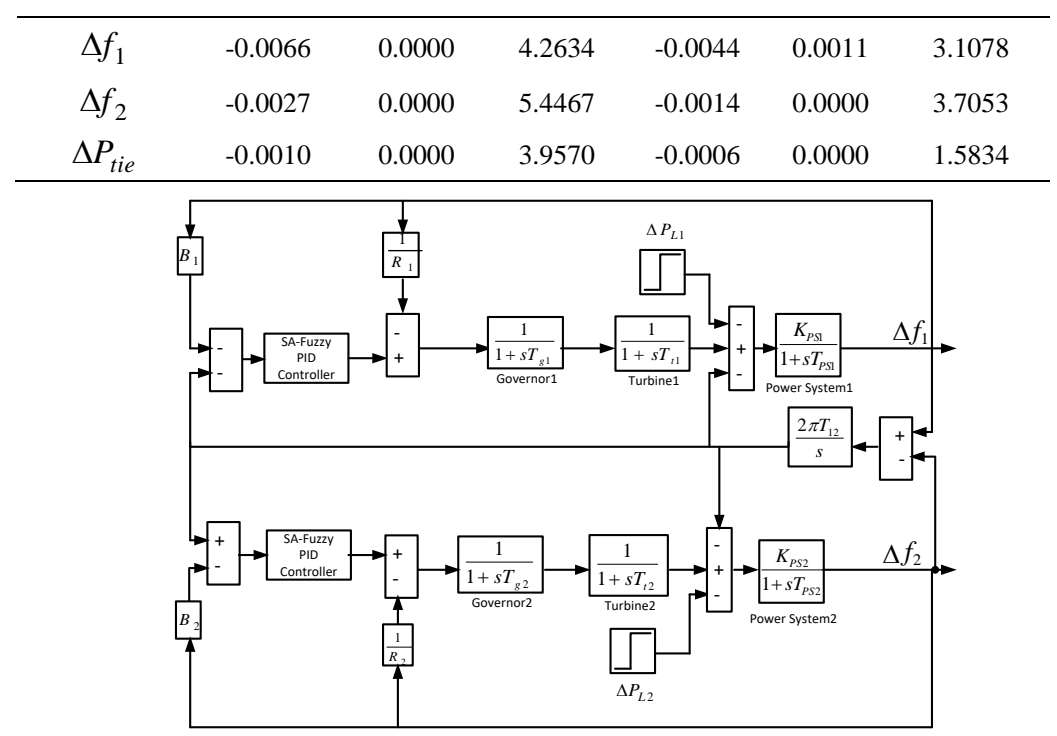

Figure 8. Model of a two-area thermal system [36].

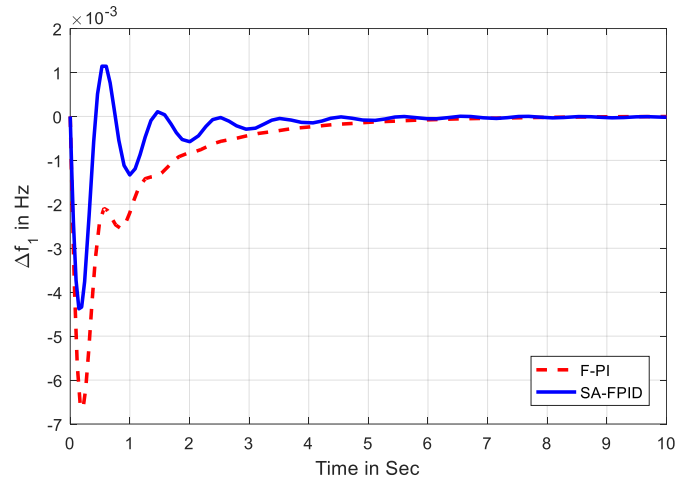

(a)

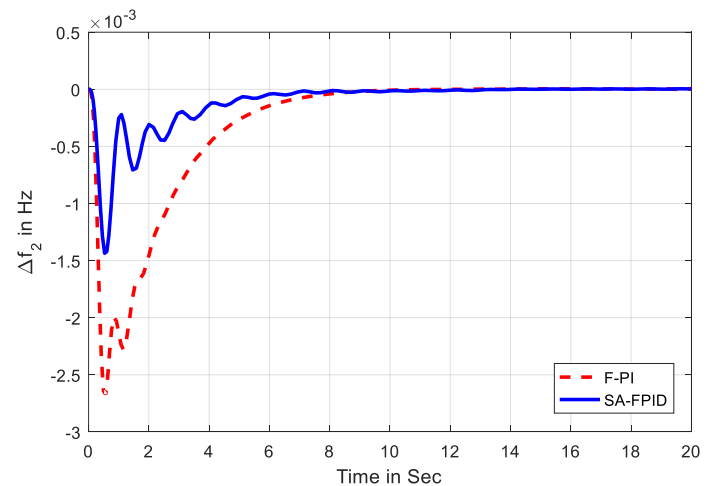

(b)

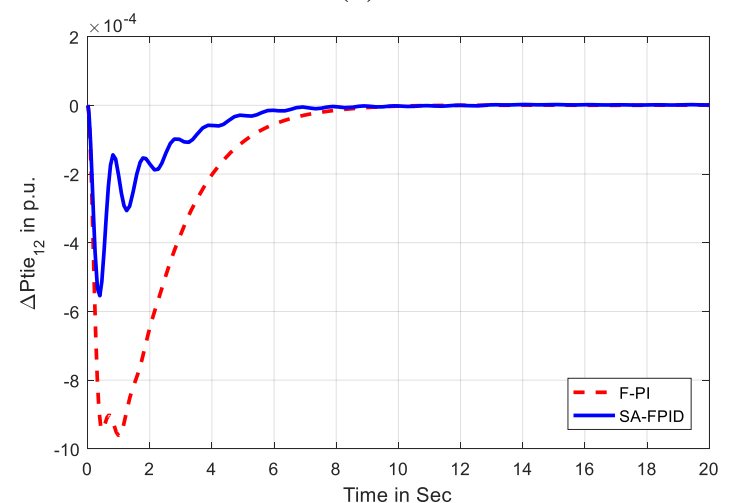


(c)

Figure 9. Transient response curve of area frequency and tie-line power, (a) Frequency deviation inarea1, (b) Frequency deviation in area-2, (c) Tie-line power deviation.

\section{CONCLUSION}

In this paper, a two area multi-source interconnected power system incorporating with HVDC link is simulated under a deregulated environment to transact scheduled and unscheduled power. The AGC issues of the proposed model is studied by implementing PID, FPID, and a novel SA-FPID controller. The gains and scaling parameters of these controllers are enumerated by applying a maiden optimisation technique named WGA. In all the cases of power transaction (Poolco, Bilateral, and Contract violation), the dynamic response of frequency deviation and tie-line power deviation by WGA based SA-FPID controller is quite superior than WGA based PID and FPID controllers. And also, the WGA based SA-FPID controller concedes an enhanced performance over FOA and PSO based different controllers such as I, PI, PID, PIDD, and IDD. Besides this, potential of SA-FPID controller over FPI controller is validated through a practical model. The excursion of the frequency deviation and tie line power deviation seldom changes to the abrupt load perturbation and parametric variations of the system. The meagre standard deviation confirms that the proposed novel WGA based SA-FPID controller is robust enough. So, an improved AGC performance is perceived by employing a novel WGA based SA-FPID controller in a deregulated power system.

\section{REFERENCES}

[1] O.I. Elgerd, "Electric Energy Systems Theory-An Introduction," second edition, Tata McGraw Hill, New Delhi, 2000 .

[2] P. Kundur, "Power System Stability and Control," Eighth Reprint, Tata McGraw Hill, New Delhi, 2009.

[3] H. Bevrani, "Robust Power System Frequency Control," Springer, New York, 2009.

[4] Ibraheem, P. Kumar, D.P. Kothari, "Recent philosophies of automatic generation control strategies in power systems,” IEEE Trans. Power Syst., vol. 20, 2005, pp.346- 357.

[5] H. Shayaghi, H.A. Shayanfar, A. Jalili, "Load frequency control strategies: a state of the art survey for the researcher," Energy Conversions and Management, vol. 50, 2009, pp. 344-354.

[6] P. Bhatt, S.P. Ghoshal, R. Roy, "Load frequency stabilization by coordinated control of thyristor controlled phase shifters and superconducting magnetic energy storage for three types of interconnected two-area power systems," Int. J. Electr. Power Energy Syst., vol. 32, 2010, pp. 1111-1124.

[7] U.K. Rout, R.K. Sahu, S. Panda, "Design and analysis of differential evolution algorithm based automatic generation control for interconnected power system,” Ain Shams Eng. J., vol. 4(3), 2013, pp.409-421.

[8] S. Panda, N.K. Yegireddy, "Automatic generation control of multi-area power system using multi-objective nondominated sorting genetic algorithm-II," Int. J. Electr. Power Energy Syst., vol. 53, 2013, pp. 54-64.

[9] L.C. Saikia, J. Nanda, S. Mishra, "Performance comparison of several classical controllers in AGC for multi-area interconnected thermal system,” Int. J. Electr. Power Energy Syst., vol. 33, 2011, pp. 394-401.

[10] S.A. Taher, M.H. Fini, S.F. Aliabadi, "Fractional order PID controller design for LFC in electric power systems using imperialist competitive algorithm," Ain Shams Eng. J., vol. 5, 2014, pp. 121-135.

[11] S. Debbarma, L.C. Saikia, N. Sinha, "Robust two-degree-of-freedom controller for automatic generation control of multi-area system,” Int. J. Electr. Power Energy Syst., vol. 63, 2014, pp. 878-886.

[12] K.P.S. Parmar, S. Majhi, D.P. Kothari, "Load frequency control of a realistic power system with multi-source power generation,” Int. J. of Electr. Power Energy Syst., vol. 42, 2012, pp. 426-433.

[13] P.K. Hota, B. Mohanty, "Automatic generation control of multisource power generation under deregulated environment," Int. J. of Electr. Power Energy Syst., vol. 75, 2016, pp.205-214.

[14] S. Debbarma, L.C. Saikia, N. Sinha, "AGC of a multi-area thermal system under deregulated environment using a non-integer controller," Int. J. of Electr. Power Systems Research, vol. 95, 2013, pp.175-183.

[15] W. Tasnin, L.C. Saikia, M. Raju, "Deregulated AGC of multi-area system incorporating dish-Stirling solar thermal and geothermal power ants using fractional order cascade controller," Int. J. of Electr. Power Energy Syst., vol. 101, 2018, pp.60-74.

[16] J. Morsali, K. Zare, M.T. Hagh, "A novel dynamic model and control approach for SSSC to contribute effectively in AGC of a deregulated power system," Int. J. of Electr. Power Energy Syst., vol. 95, 2018, pp. 239-253.

[17] R. Rajbongshi, L.C. Saikia, "Performance of coordinated interline power flow controller and power system stabilizer in combined multiarea restructured ALFC and AVR system," Wiley, 2019.

[18] N. Kumar, B. Tyagi, V. Kumar, "Multiarea Deregulated Automatic Generation Control Scheme of Power System Using Imperialist Competitive Algorithm Based Robust Controller," IETE journal of Research, 2017.

[19] J.R. Nayak, B. Shaw, "Implementation of Quasi-Oppositional-Based GHS Optimized Fractional Order PID Controller in Deregulated Power System," Advances in intelligent systems and computing, 2019.

[20] B. Baskari, B. Paramasivam, I.A. Chidambaram, "Ancilliary service requirement based automatic generation control assessment in a deregulated power system with HES and IPFC units,"Journal of Engineering and Technology, 2018, pp. 3092-3115

[21] K.P.S. Parmar, S. Majhi, D.P. Kothari, "LFC of an interconnected power system with multi-source power generation in deregulated power environment," Int. J. of Electr. Power Energy Syst., vol. 54, 2014, pp.277-286. 
[22] A. Prakash, S. Murali, R. Shankar, R. Bhushan, "HVDC tie-link modeling for restructured AGC using a novel fractional order cascade controller," Int. J. of Electr. Power Systems Research., vol. 170, 2019, pp.244-258.

[23] Ibraheem, Nizamuddin, T.S. Bhatti, "AGC of two area power system interconnected by AC/DC links with diverse sources in each area,” Int. J. of Electr. Power Energy Syst., vol. 55, 2014, pp.297-304.

[24] R. Shankar, A. Kumar, U. Raj, K. Chatterjee, "Fruit fly algorithm-based automatic generation control of multiarea interconnected power system with FACTS and AC/DC links in deregulated power environment," Wiley, 2018.

[25] Y. Arya, N. Kumar, "AGC of a multi-area multi-source hydrothermal power system interconnected via AC/DC parallel links under deregulated environment”, International Journal of Electrical Power \& Energy Systems, 75, 2016, pp.127-138.

[26] C.S. Rao, S.S. Nagaraju, P.S. Raju, "Automatic generation control of TCPS based hydrothermal system under open market scenario: a fuzzy logic approach,” Int. J. of Electr. Power Energy Syst., vol. 31, 2009, pp.315-322.

[27] M. Deva Brinda, A. Suresh, M.R. Rashmi, "Implementation of Web Context to Monitoring Load Frequency Control in a Deregulated Environment with Consideration of the Governor and Boiler Dynamics," Wireless Pers Communication, 2018.

[28] A. Fathy, A.M. Kassem, Y. Almoataz, Abdelaziz, "Optimal design of fuzzy PID controller for deregulated LFC of multiarea power system via mine blast algorithm," Neural computing and Application, 2018.

[29] M. Ghanamijaber, "A hybrid fuzzy-PID controller based on gray wolf optimization algorithm in power system," Evolving System, 2018.

[30] H. Afrakhte, S.H. Rouhani, "Optimal participating of the distributed generation sources in the re-structured power systems with optimized fuzzy logic controller," Journal of intelligent and fuzzy system, vol. 1, 2016, pp. 1-15

[31] Y. Arya, N. Kumar, "BFOA-scaled fractional order fuzzy PID controller applied to AGC of multi-area multi-source electric power generating systems", Swarm and Evolutionary Computation, 32, 2017, pp.202-218.

[32] M. Gheisamejad, M.H. Khooban, "Design an optimal fuzzy fractional proportional integral derivative controller with derivative filter for load frequency control in power systems," Trans. of the Institute of Measurement and Control, 2019, pp.1-19.

[33] Y. Arya, "AGC of restructured multi-area multi-source hydrothermal power systems incorporating energy storage units via optimal fractional-order fuzzy PID controller", Neural Computing and Applications, 31(3), 2019, pp.851872.

[34] A. Shefaei, B.M. Ivatloo, "Wild Goats Algorithm: An Evolutionary Algorithm to Solve the Real-World Optimization Problems,” IEEE Trans. on Industrial Informatics, vol. 14(7), 2018, pp.2951-2961.

[35] B. Mohanty, P.K. Hota, "Comparative performance analysis of fruit fly optimisation algorithm for multi-area multisource automatic generation control under deregulated environment," IET journals, 2015.

[36] Y. Arya, "Automatic generation control of two-area electrical power systems via optimal fuzzy classical controller," Journal of the Franklin Institute, 355(5), 2018, pp.2662-2688. 